\title{
Waste Heat Recovery by Means of Organic Rankine Cycle (ORC) System Coupled with Two-Phase Closed Thermosyphons
}

\author{
Van Long Lê a, 1, *, Sébastien Declaye ${ }^{\mathrm{a}, 2}$, Xavier Dumas ${ }^{\mathrm{b}, 3}$, Ludovic Ferrand ${ }^{\mathrm{b}, 4}$, and Vincent Lemort ${ }^{\text {a, }}$, \\ a The University of Liège, Liège, Belgium \\ ${ }^{\mathrm{b}}$ CMI Industry, Guyancourt, France \\ Email: ${ }^{1}$ vanlong.le@ulg.ac.be, ${ }^{2}$ Sebastien.Declaye@ulg.ac.be, ${ }^{3}$ xavier.dumas@ cmigroupe.com, ${ }^{4}$ \\ ludovic.ferrand@cmigroupe.com, ${ }^{5}$ vincent.lemort@ulg.ac.be
}

Received 21 September 2016, Revised 01 March 2017, Accepted 27 March 2017

\begin{abstract}
This paper aims at assessing the performance of a waste heat-to-power plant by means of an ORC (Organic Rankine Cycle) system coupled with two-phase closed thermosyphons (or gravity-assisted heat pipes or wickless heat pipes). The heat exchanger, made up of two-phase closed thermosyphons, is used for conveying heat from exhaust stream to ORC working fluid. In reality, a hot oil loop or a pressurized hot water loop or a saturated steam loop or even a direct evaporator is often used to transfer heat from the heat source to the ORC system. However, installing a heat exchanger directly in the hot gas paths of ORC system evokes the concerns for the flammability and/or toxicity of organic working fluids especially when the heat source has a relatively high temperature. Also the use of an intermediate heat carrier loop such as thermal oil or saturated steam or pressurized water loop is costly and involves installation of comparatively heavy components. In principle, the use of two-phase closed thermosyphons for capturing and transporting heat from a waste heat source to organic working fluid is less expensive than utilizing an intermediate heat transfer loop and eliminates safety issues as in the case of direct installation of an ORC evaporator in the hot gas paths.
\end{abstract}

\section{Keywords: Waste heat recovery; ORC; two-phase closed thermosyphon; performance evaluation.}

\section{Introduction}

The present study has been carried out in the context of ORCAL (stands for waste heat recovery by means of ORC system connected to gravity-assisted heat pipes or twophase closed thermosyphons) project within collaboration between the University of Liège and C.M.I. (Cockerill Maintenance \& Ingénierie) group. The main objective of this project is to capture and convert heat from exhaust stream of a rolling mill reheating furnace (RHF) into electricity via an ORC system connected to two-phase closed thermosyphons as shown in Figure 1. The current installation has already comprised a heat exchanger (i.e. airpreheater) for recovering heat from RHF off-gas to preheat the combustion air from ambient temperature up to about $500^{\circ} \mathrm{C}$. The supplementary waste heat recovery system (i.e. thermosyphons-ORC system) would be placed upstream the air-preheater where the exhaust gases are characterized by a temperature of about $820^{\circ} \mathrm{C}$. As the air feeding natural gas combustion of $\mathrm{RHF}$ has to be maintained at $500^{\circ} \mathrm{C}$ to ensure the furnace efficiency, the current air-preheater must be redesigned (i.e. increasing heat transfer surface area) and the new temperature of flue gases, after being cooled down by the thermosyphons-based heat exchanger, incoming the air-preheater must be greater than $500^{\circ} \mathrm{C}$. For the initial system design, the temperature drop of the exhaust gases across the thermosyphons heat exchanger is fixed to $200 \mathrm{~K}$.

To date, there are not many scientific or technical publications on the use of two-phase closed thermosyphons for transferring heat from exhaust stream to ORC system.
The combination between ORC and heat pipes or two-phase closed thermosyphons is only reported in some patents [1, 2]. In the first patent [1], a special type of heat pipe, i.e. inorganic coated heat pipe or also called Qu-type heat pipe, is used for conveying heat from heat source, e.g. exhaust gases, to an ORC working fluid. As described in this patent, Qu-type heat pipe is a type of solid-state heat pipe which operates somewhat similarly to liquid-vapour heat pipes (e.g. two-phase closed thermosyphon) but does not use a liquid-vapour material to transfer heat from one end to other end of pipe. In a Qu-type heat pipe, the internal heat transfer material comprises three layers of various combinations of metals such as: Sodium, Beryllium, Manganese, Aluminium, Calcium, etc. The three layers can be applied to a conduit and then heat polarized to form heat transfer devices that transfer heat. In the second patent [2], the two-phase closed thermosyphons were used to recover the heat of fumes or exhaust gases by using an ORC system or a heat pump or a thermoelectric module. As claimed in this patent, the evaporator section of one or many twophase closed thermosyphons are submersed in one fluidized bed of sand whose the average size is around $400 \mu \mathrm{m}$ for improving the heat transfer between fumes and thermosyphons wall. Both technologies present the advantages for transferring the heat from hot fumes or exhaust gases to ORC working fluid. However they also present some drawbacks, such as high manufacturing cost for Qu-type heat pipes and high pressure drop for the 
mixture between a fluidized bed and two-phase closed thermosyphons.

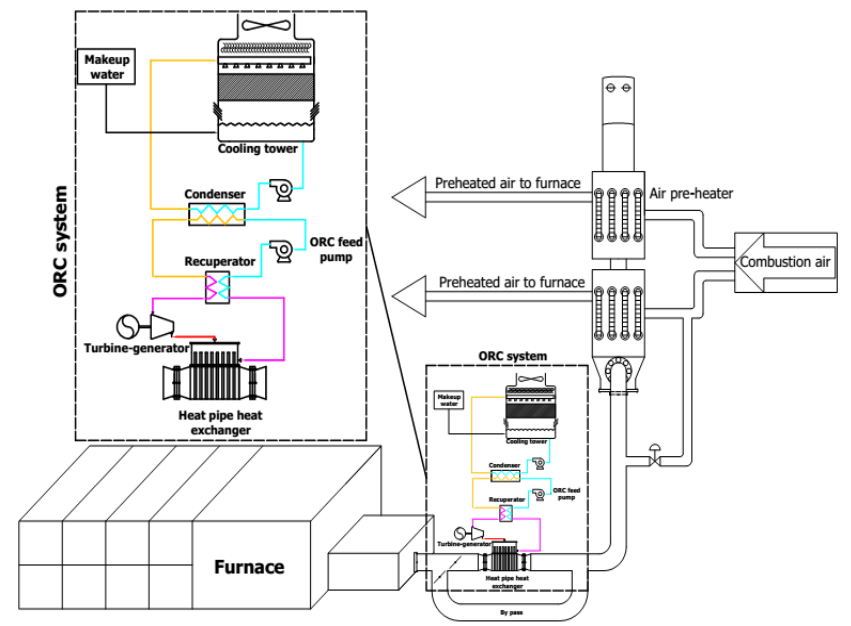

Figure 1. Schematic of waste heat recovery system using ORC connected to two-phase closed thermosyphons.

This work aims at examining the use of traditional twophase closed thermosyphons heat exchanger for transferring heat from hot gases to ORC working fluid.

\section{Two-Phase Closed Thermosyphon Heat Exchanger}

The two-phase closed thermosyphon (also called gravity-assisted heat pipe or wickless heat pipe) is shown in Figure 2. An amount of working fluid (e.g. water, refrigerant, hydrocarbons, etc.) is placed in a tube from which the air and all other gases are then evacuated and the tube sealed [3]. The lower end (also called evaporator section) of the tube is heated causing the liquid to vaporise and the vapour to move to the cold end (also called condenser section) of the tube where it is condensed. The evaporator and condenser section are separated by an adiabatic section. The condensate is returned to the hot end by gravity. Since the latent heat of vaporization of water is very large, substantial quantities of heat can be transported with a very small temperature difference from end to end. Consequently, the structure will have a great effective thermal conductance. The overall performance of thermosyphon in terms of thermal resistance is [4]:

$\dot{Q}=\frac{\Delta T}{R_{t o t}}$

Where $\dot{Q}$ is the rate of heat transferred by thermosyphon, $\mathrm{W}, \Delta T=\left(T_{\infty, e}-T_{\infty, c}\right)$ is the effective overall temperature difference, $\mathrm{K}, R_{t o t}$ is the overall thermal resistance of thermosyphon, $\mathrm{K} / \mathrm{W}$.

The thermal resistances of a two-phase closed thermosyphon described in [5] can be seen in Figure 2.
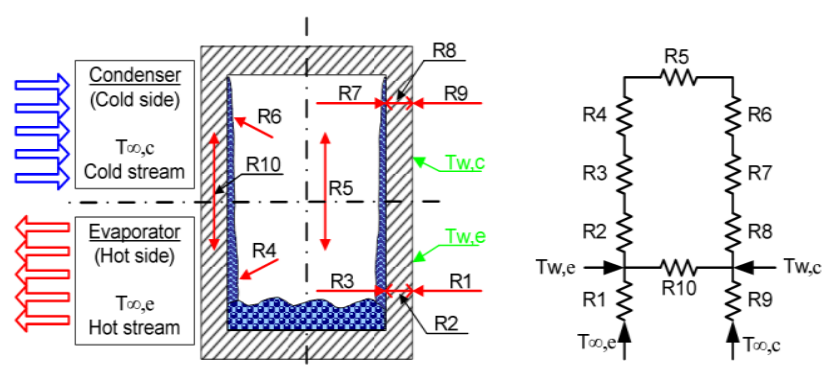

Figure 2. Thermosyphon and thermal resistances diagram [6].
Where $R_{1}$ and $R_{9}$ are combined thermal resistance of convection and radiation outside the evaporator section and thermal resistance outside the condenser section of thermosyphon, respectively.

$R_{2}$ and $R_{8}$ are thermal resistances of conduction through the evaporator and condenser walls, respectively. $R_{3}$ and $R_{7}$ are thermal resistances of the boiling and condensation of thermosyphons working fluid, respectively. $\mathrm{R}_{4}$ and $\mathrm{R}_{6}$ are thermal resistances at the surface of the liquid-vapour interface in the evaporator and condenser section, respectively. These resistances are small and can be neglected. $R_{5}$ is thermal resistance due to vapour pressure drop from evaporator section to condenser section. This resistance can also be neglected.

$\mathrm{R}_{10}$ is thermal resistance along the thermosyphon. This resistance is too large and can be neglected.

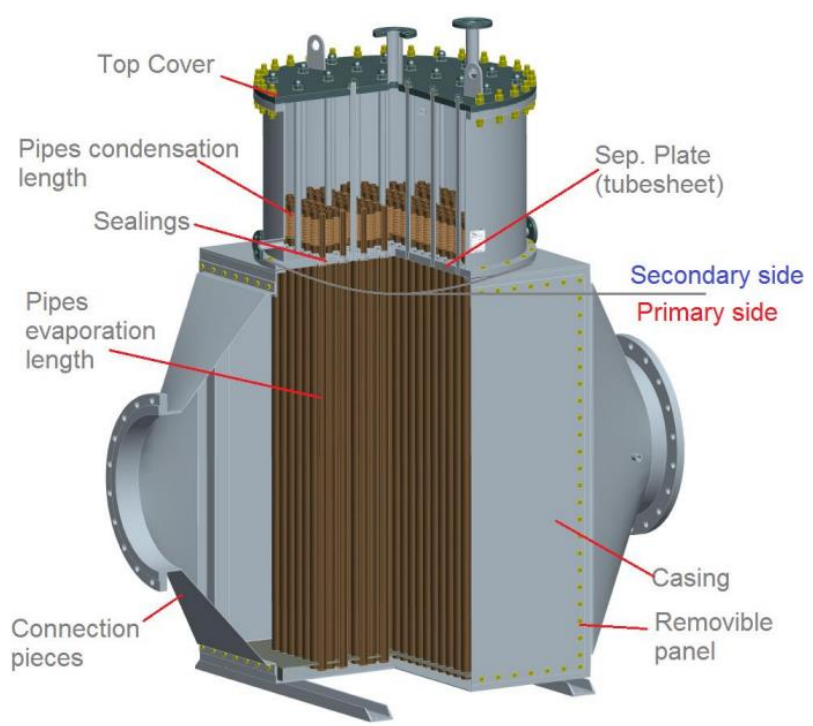

Figure 3. Schematic of a two-phase closed thermosyphon heat exchanger [7].

A two-phase closed thermosyphon heat exchanger in which groups of two-phase closed thermosyphons are arranged in a casing, the centre of which is partitioned, a high temperature fluid flows on one side, a low temperature fluid flows on the other side, thereby transferring the heat of the high temperature fluid to the low temperature fluid via fluid sealed in the two-phase closed thermosyphons, is shown in Figure 3. In many countries, the use of thermosyphon heat exchangers is quite new, but other countries, such as China, has applied this technology for decades [8]. Indeed, the geometric flexibility [9], low maintenance, low cost and compactness make thermosyphon heat exchangers attractive when compared to the other technologies (e.g. tube-and-shell and plate heat exchangers) [8].

\subsection{Two-Phase Thermosyphon Working Fluid and Material}

The choice of the working fluid is one of the most important parameters for thermosyphon design. Several aspects must be considered for instance: range of working temperature, chemical compatibility between the working fluid and thermosyphon material, vapour pressure, stability, toxicity, etc. A useful guide for selecting two-phase thermosyphon working fluid is to compare different fluids in 
function of figure of merit $\left(\mathrm{FOM}_{\mathrm{t}}\right)$, which has the dimension $\frac{k g}{K^{3 / 4} s^{5 / 2}}$, defined as follow [3]:

$\mathrm{FOM}_{t}=\left(\frac{\rho_{l}^{2} k_{l}^{3} \Delta h_{l v}}{\mu_{l}}\right)^{1 / 4}$

The thermo-physical properties that compose the figure of merit appear in the expression of thermal resistance in condensation of thermosiphon working fluid as follow [5]:

$R_{7}=\frac{0.235 \dot{Q}^{1 / 3}}{D^{4 / 3} g^{1 / 3} L_{c} \mathrm{FOM}_{t}^{4 / 3}}$

Although, these numbers of merit have no meaning in themselves, they enable to compare the performance of different fluids [10]. The higher figure of merit is, the better the thermosyphon performance is. The operating temperature of thermosyphon situates between the temperature of fumes and evaporating temperature of ORC working fluid. The heat transfer coefficient on the fumes side is much lower than the coefficient on the organic working fluid side (with phase change transformation). As a consequence, the temperature of thermosyphon working fluid is closer to the temperature of ORC working fluid than fumes temperature. Based on this statement, the temperature of working fluid inside thermosyphon is probably within $150-300^{\circ} \mathrm{C}(423-573 \mathrm{~K})$. In this temperature range, the water presents a relatively high figure of merit as shown in Figure 4. It seems to be logic to approve this fluid considering other advantages for example stability, nontoxicity, availability, low price, and familiarity, etc. The main concern about water is the vapour pressure, which can increase significantly with the temperature. In these cases, the casing material must be selected so that it can tolerate the vapour pressure [8]. It is important to note that whilst the figures of Merit are useful guides, they are not sole criterion. Other factors such as vapour pressure and materials compatibility are also important considerations.

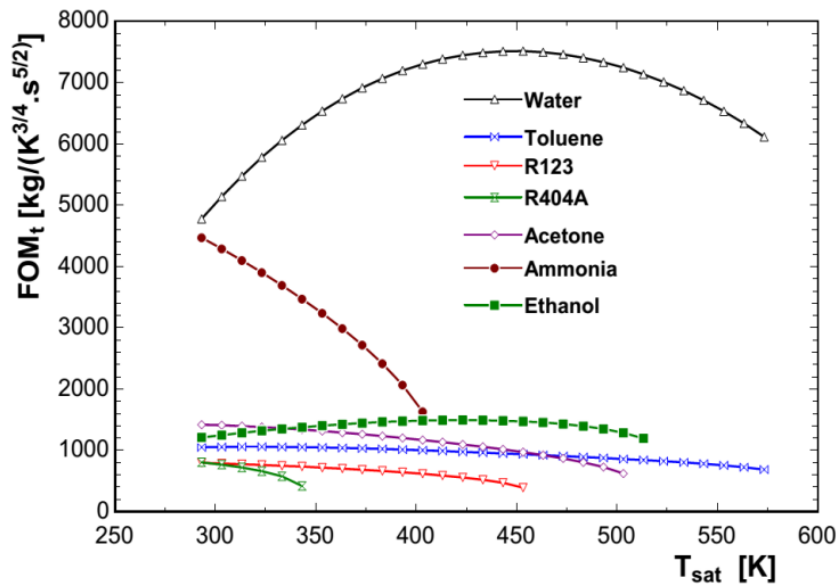

Figure 4. Figure of merit for different two-phase closed thermosyphon working fluid.

In turn, the selection of tube material is also a very important parameter for the design of thermosyphon [8]. The tube has to be compatible with the working medium and the environment to stand the mechanical strength needs of the thermosyphon. The working fluid and tube material should not react chemically to avoid the generation of non- condensable gases which are one of the most common impurities of thermosyphon working fluid. During the operation, the non-condensable gases are pushed to the upper end of the condenser region, blocking part of the condenser and causing a reduction in the thermal performance of the device. The working fluid and the functioning temperature are main input parameters for the selection of the tube material and the thickness. Table 1 shows a list of compatibility between common tube materials and working fluids. With water as thermosyphon working fluid, the tube material could be Copper, Monel, Silica, Nickel, Stainless or Carbon Steel. As the reheating furnace off-gases, i.e. exhaust gases of natural gas combustion, are clean without the presence of corrosive components, the couple Water/Carbon Steel was preliminarily chosen as working fluid/tube material of thermosyphon in the current study.

Table 1. Working fluid and tube material compatibilityt [8].

\begin{tabular}{|c|c|c|}
\hline & Recommended & Not recommended \\
\hline Ammonia & $\begin{array}{l}\text { Aluminium, Steel, Nickel, } \\
\text { Stainless steel }\end{array}$ & \multirow[t]{2}{*}{ Copper } \\
\hline Acetone & $\begin{array}{l}\text { Copper, Silica, Aluminium, } \\
\text { Stainless steel a }\end{array}$ & \\
\hline Methanol & $\begin{array}{l}\text { Cooper, Stainless steel, } \\
\text { Carbon steel, Silica }\end{array}$ & Aluminium \\
\hline Mercury & Stainless steel & $\begin{array}{l}\text { Nickel, Inconel, } \\
\text { Titanium, Niobium }\end{array}$ \\
\hline Water & $\begin{array}{l}\text { Copper, Monel, Silica }{ }^{\text {a, b }} \text {, } \\
\text { Nickel }^{\text {a, b }} \text {, Stainless steel }{ }^{\text {a, b }} \text {, } \\
\text { Carbon steel }^{\text {a, b }}\end{array}$ & \multirow[t]{3}{*}{$\begin{array}{l}\text { Stainless steel }{ }^{\mathrm{a}, \mathrm{b}} \\
\text { Carbon steel }{ }^{\mathrm{a}, \mathrm{b}} \\
\text { Aluminium, Silica, } \\
\text { Inconel, Nickel }\end{array}$} \\
\hline $\begin{array}{l}\text { Dowtherm } \\
\text { A }\end{array}$ & $\begin{array}{l}\text { Copper, Silica, Stainless } \\
\text { steel }^{\text {b }}\end{array}$ & \\
\hline Naphthalene & Carbon steel, Stainless steel & \\
\hline Potassium & Stainless steel, Inconel & Titanium \\
\hline Sodium & Stainless steel, Inconel & Titanium \\
\hline Silver & Tungsten, Tantalum & Rhenium \\
\hline $\begin{array}{l}{ }^{\mathrm{a}} \text { Considered } \\
{ }^{\mathrm{b}} \text { Recommenc }\end{array}$ & $\begin{array}{l}\text { patible for some authors a } \\
\text { with caution }\end{array}$ & compatible for others \\
\hline
\end{tabular}

\subsection{Theoretical Performance of Thermosyphon}

The performance and operational temperatures of thermosyphon are determined by resolving the system of equations

$\left\{\begin{array}{l}\dot{Q}=\frac{T_{\infty, e}-T_{w e, o}}{R_{1}} \\ \dot{Q}=\frac{T_{w e, o}-T_{w e, i}}{R_{2}} \\ \dot{Q}=\frac{T_{w e, i}-T_{v, e}}{R_{3}} \\ \dot{Q}=\frac{T_{v, c}-T_{w c, i}}{R_{7}} \\ \dot{Q}=\frac{T_{w c, i}-T_{w c, o}}{R_{8}} \\ \dot{Q}=\frac{T_{w c, o}-T_{\infty, c}}{R_{9}} \\ T_{v, e}=T_{v, c}\end{array}\right.$ 
Here $\dot{Q}$ is the rate of heat transmitted by thermosiphon, $T_{\infty, e}$ and $T_{\infty, c}$ are temperatures of fluids outside evaporator and condenser sections of thermosyphon, i.e. temperatures of exhaust gases and organic fluid, respectively, $T_{w e, o}$ and $T_{w e, i}$ are temperatures at outer and inner surfaces of evaporator section of thermosyphon, respectively, $T_{v, e}$ and $T_{v, c}$ are temperatures of thermosyphon working fluid at evaporator and condenser sections, respectively, $T_{w c, o}$ and $T_{w c, i}$ are temperatures of outer and inner surfaces of condenser section of thermosyphon, respectively.

The correlations for determining the internal resistances of thermosyphon, i.e. $R_{2}$ to $R_{8}$, can be found in the reference [5]. The external resistance outside evaporator section of thermosyphon is

$$
R_{1}=\frac{1}{A_{e, o} \alpha_{e, o}}
$$

where $A_{e, o}$ is the outer surface of evaporator region, $\mathrm{m}^{2}$ and $\alpha_{e, o}$ is the heat transfer coefficient outside the evaporator zone of thermosyphon, $\mathrm{W} /\left(\mathrm{m}^{2} \mathrm{~K}\right)$.

As the exhaust gases contain the asymmetric molecules, i.e. $\mathrm{H}_{2} \mathrm{O}$ and $\mathrm{CO}_{2}$, the heat transfer coefficient is the sum of radiative and convective heat transfer coefficients. While the convective heat transfer coefficient, $\alpha_{\text {conv }}$, is calculated using the correlation of Zukauskas [11], the radiative one, $\alpha_{\text {rad }}$, is determined as [12]

$\alpha_{\text {rad }}=\sigma \frac{\varepsilon_{f} T_{f}^{4}-\alpha_{f} T_{w}^{4}}{T_{f}-T_{w}}=5.67 \times 10^{-8} \frac{\varepsilon_{f} T_{f}^{4}-\alpha_{f} T_{w}^{4}}{T_{f}-T_{w}}$

where $\sigma$ is the Stefan-Boltzmann constant, $\mathrm{W} /\left(\mathrm{m}^{2} \mathrm{~K}^{4}\right), \varepsilon_{f}$ is fumes emissivity, $\alpha_{f}$ is the fumes absorptivity, $T_{f}$ is fumes temperature in $\mathrm{K}, T_{w}$ is temperature at the outer surface of evaporator section of thermosyphon in $\mathrm{K}$.

The fumes emissivity and absorptivity are computed as described in the reference [12]. The thermal resistance outside condenser region is calculated as follow

$$
R_{9}=\frac{1}{A_{c, o} \alpha_{c, o}}
$$

where $A_{c, o}$ is the outer surface of condenser region, $\mathrm{m}^{2}$, $\alpha_{c, o}$ is the heat transfer coefficient, $\mathrm{W} /\left(\mathrm{m}^{2} . \mathrm{K}\right)$, of pool boiling calculated by Cooper correlation [13] as follow

$$
\alpha_{c, o}=55 M M^{-0.5} q^{0.67} p_{r}^{0.12}\left[-\log _{10}\left(p_{r}\right)\right]^{-0.55}
$$

where $\mathrm{MM}$ is the molecular weight of organic fluid, $\mathrm{g} / \mathrm{mol}$, $q$ is the heat flux, $\mathrm{W} / \mathrm{m}^{2}, p_{r}$ is the reduced pressure defined as the ratio of evaporating pressure to the critical pressure of organic fluid.

As the temperature difference across a thermosyphon is augmented, the overall rate of heat transfer rises until a maximum is reached [5]. This may be due to a boiling crisis (burnout limit), an excessive pressure drop of vapour or a failure in the supply of liquid to the heated surface (dry-out and counter-current flow limit). In the case of two-phase closed thermosyphon, three most important limitation phenomena are dry-out, burnout and counter-current flow limit (CCFL). The boiling limit (or burnout limit) takes place when a stable film of vapour is formed between the liquid of thermosyphon working fluid and the heated wall of the evaporator. The term "dry-out" implies that the volume of the liquid fill is not sufficient to cover the entire pipe above the pool with a film of liquid. Even when there is sufficient liquid present in the thermosyphon to avoid dry-out occurring, the overall rate of heat transfer is subject to another limit, i.e. CCFL; this occurs when the rate of entrainment of liquid by the vapour inhibits the downward flow of liquid.

While dry-out limitation usually can be avoided by selecting a sufficient fill ratio for the thermosyphon. The burnout and the counter-current flow limits must be carefully determined. The correlation for calculating these limits are well described by Groll and Rösler [14]. It is recommended that the thermosyphon is designed to operate at less than $50 \%$ of the maximum rate of heat transfer [5], i.e. the minimum value of heat transfer rate at burnout, dryout and counter-current flow limit. When the calculated rate of heat transferred by thermosyphon is greater than $50 \%$ of its maximum heat transfer rate, the geometrical parameters, e.g. thermosyphon diameter, would be modified to satisfy the limitation.

The Table 2 recaps the geometrical parameters such as thermosyphon diameters, the lengths of evaporator, condenser and adiabatic sections; as well as the rate of heat transferred by the thermosyphon; the heat transfer rates at burnout and CCFL; and the thermal resistances of thermosyphon. The lowest value of heat transfer rates at limitation is for CCFL. This will therefore determine the maximum rate of heat transfer that could be obtained in the thermosyphon. The calculated rate of heat transfer of thermosyphon is only $46.5 \%$ of the maximum. The overall thermal resistance is of $0.02505 \mathrm{~K} / \mathrm{W}$. The thermal resistance on fumes side represents more than $90 \%$ of overall thermal resistance.

Table 2. Summary table of thermosyphon calculation.

\begin{tabular}{lll}
\hline Parameters & Value & Unit \\
\hline$D_{o}$ & 48 & $\mathrm{~mm}$ \\
$D_{\mathrm{i}}$ & 41 & $\mathrm{~mm}$ \\
$L_{e}$ & 3400 & $\mathrm{~mm}$ \\
$L_{a}$ & 200 & $\mathrm{~mm}$ \\
$L_{c}$ & 1200 & $\mathrm{~mm}$ \\
$\dot{Q}$ & 24.2 & $\mathrm{~kW}$ \\
$\dot{Q}_{\text {burnout }}$ & 1541 & $\mathrm{~kW}$ \\
$\dot{Q}_{\mathrm{CCFL}}$ & 52.4 & $\mathrm{~kW}$ \\
$\Delta \mathrm{T}$ & 600 & $\mathrm{C}$ \\
$R_{\mathrm{tot}}$ & 0.02505 & $\mathrm{~K} / \mathrm{W}$ \\
$R_{1}$ & 0.02273 & $\mathrm{~K} / \mathrm{W}$ \\
$R_{2}$ & 0.0002066 & $\mathrm{~K} / \mathrm{W}$ \\
$R_{3}$ & 0.0002432 & $\mathrm{~K} / \mathrm{W}$ \\
$R_{7}$ & 0.0005795 & $\mathrm{~K} / \mathrm{W}$ \\
$R_{8}$ & 0.0005978 & $\mathrm{~K} / \mathrm{W}$ \\
$R_{9}$ & 0.00006929 & $\mathrm{~K} / \mathrm{W}$ \\
\hline
\end{tabular}




\section{Organic Rankine Cycle}

In many existing waste heat to power systems, steam turbines are often used for converting heat into electricity in energy intensive industries. The waste heat recovery boilers capture the energy of the exhaust gases to vaporise water and produce saturated or superheated steam which is then expanded through a steam turbine [15]. Indeed, the steam power cycle system is typically utilized for plants over 10 MWel and extending up to $50 \mathrm{MWel}$ and above. In these cases and where the industrial processes generate a steady flow of high temperature exhaust gases, the superheated steam cycles are often preferred to maximize the efficiency in converting heat into electrical power. However, such systems are often considered un-economic for waste heat to power plants with a power output lower than $10 \mathrm{MWel}$ owing to high Operation and Maintenance cost (e.g. operators must be certified as steam engineers, water quality requires special care etc.). Moreover, when the process heat source is highly variable, steam turbines cannot be easily employed.

As a result of the aforementioned factors, an ORC system, which operates in a similar way to the steam Rankine cycle system, but uses an organic compound instead of water as working fluid, is often considered for catching and transforming waste heat into electricity at smaller scale. Indeed, using organic fluids with higher molecular weight than water can result in greater turbine efficiency and thus less costly expanders. Furthermore, the low specific enthalpy drop of organic vapour requires a higher mass flow rate through the turbine for the same power output [16]. This allows the blades to be larger and satisfies the full-admission condition of the turbine, even for small power outputs. Consideration of these factors leads to higher nozzle and blade efficiencies [16]. Regarding vapour partial condensation during expansion process, it is interesting to note that many common organic compounds exhibit a vapour saturation curve on the T-s (Temperature - entropy) diagram with an approximately zero (isentropic fluid) or positive (dry fluid) slope ds/dT. In consequence, isentropic expansion of saturated organic vapour results in saturated or superheated vapour, so that erosion of blades is avoided. Additionally, ORC technology offers other advantages such as simple start up procedures, automatic and continuous operation, simple maintenance procedure, no operator attendance required; long life of the plant (> 20 years), no need to demineralize water, etc.

\subsection{Working Fluid}

Regarding the working fluid selection for ORC power plant, many organic compounds have been studied and used as working medium over the last decades. The working fluid selection is in general influenced by many factors, e.g. thermo-physical properties, toxicity, flammability, thermal stability, availability, regulations, etc. Recently, to control emissions from fluorinated greenhouse gases (F-gases), including hydrofluorocarbons, the European Union has adopted two legislative acts [17], i.e. the "MAC directive" on air-conditioning system used in small motor vehicle and "F-gas regulation" which covers all other key applications in which F-gases are used. While MAC directive prohibits the use of F-gases with a GWP (Global Warming Potential) being higher 150 in all new car and vans produced from 2017 , the "F-gas regulation" follows two tracks of action [18]:
- Improving the prevention of leaks from equipment containing F-gases

- Avoiding the use of F-gases where environmentally superior alternative are cost-effective.

For this study, Cyclopentane, the characteristics of which are presented in Table 3, is chosen as ORC working fluid as recommended in the reference [19]. However the other organic fluids should be also investigated to find out the most appropriate working medium for such system. As reported in the reference [19], Cyclopentane should be a fairly stable compound to be used as a working fluid when bulk fluid temperature are preserved below $300^{\circ} \mathrm{C}$ and air is excluded from the system. Actually, several ORC markers such as General Electric Oil \& Gas [20], Atlas Copco [21] use Cyclopentane as ORC working fluid.

Table 3. Cyclopentane characteristics.

\begin{tabular}{lllllllll}
\hline Form. & $\begin{array}{l}\mathrm{MM} \\
\mathrm{g} / \mathrm{mol}\end{array}$ & $\begin{array}{l}T_{b} \\
{ }^{\circ} \mathrm{C}\end{array}$ & $\begin{array}{l}T_{\text {crit }} \\
{ }^{\circ} \mathrm{C}\end{array}$ & $\begin{array}{l}P_{\text {crit }} \\
\text { bar }\end{array}$ & $\begin{array}{l}T_{\text {auto }} \\
{ }^{\circ} \mathrm{C}\end{array}$ & NFPA & ODP & GWP \\
\hline $\mathrm{C}_{5} \mathrm{H}_{10}$ & 70.15 & 49.3 & 238.6 & 45.7 & 361 & $1 / 3 / 0$ & 0 & $<25$
\end{tabular}

\subsection{Components}

The major components of the ORC system considered in this study consist of a pump for rising the pressure of working fluid and transporting it through other components; an Internal Heat Exchanger (IHE) for recuperating the heat of vapour exiting the turbine to preheat the liquid from the pump; an evaporator (i.e. thermosyphons-based heat exchanger described in the section 2) for transporting the heat from exhaust gases to ORC working fluid; a turbogenerator for transforming thermal energy into electricity and a condenser for cooling down and condensing the working fluid before it would be pumped again to high pressure. Several basic equations for the main components of ORC system are described below.

Pump isentropic efficiency may be computed by the following equation:

$\eta_{s, p}=\frac{h_{s, o u t, p}-h_{i n, p}}{h_{\text {out }, p}-h_{\text {in }, p}}$

The available NPSH (Net Positive Suction Head) is defined as the difference between the liquid pressure at the pump inlet and the vapour pressure of the liquid, expressed as a head [22] calculated by Eq. (10). To avoid pump cavitation, the available NPSH is suggested to be greater than $1.52 \mathrm{~m}$ (5 ft.) for a centrifugal pump [22]. Therefore, the liquid should be at subcooled state at condenser outlet. In this study, a sub-cooling degree of $10 \mathrm{~K}$ is set for avoiding pumping cavitation.

$\mathrm{NPSH}_{p}=\frac{P_{i n, p}-P_{s a t}}{g \rho_{i n, p}}$

where $P_{\text {sat }}$ is saturated pressure of the liquid at inlet temperature.

Heat transfer rate of internal heat exchanger is calculated as follow:

$\dot{Q}_{\text {IHE }}=\dot{m}_{\text {ORC }}\left(h_{\text {in }, h, I H E}-h_{\text {out }, h, I H E}\right)$ 
Regarding the thermosyphons-based evaporator, assuming that there are no losses, the actual heat transfer rate is

$$
\dot{Q}_{h}=\dot{C}_{h}\left(T_{h, i}-T_{h, o}\right)=\dot{m}_{O R C}\left(h_{i n, t}-h_{\text {out }, c, I H E}\right)
$$

The turbine isentropic efficiency is determined by the following equation:

$$
\eta_{s, t}=\frac{h_{i n, t}-h_{\text {out }, t}}{h_{\text {in }, t}-h_{\text {out }, s, t}}
$$

Whereas the pump isentropic efficiency is fixed for this study, the turbine one is determined by using the correlation described in the work of Astolfi and Macchi [23]. This correlation is indeed used in order to predict the efficiency of single-stage axial-flow turbine in function of size parameter (SP) and volume flow ratio $\left(V_{r}\right)$ determined as in the Eqs. (14) and (15), respectively. The correlation is the result of an optimization study carried out on a large number of turbine stages. The turbine stage efficiency is found to be a function of three main parameters: volume flow ratio which accounts for the compressibility effects, size parameter which accounts for the actual turbine dimensions and specific speed which can either be optimized or selected as an independent variable [24]. For this study, the turbine stage efficiency is predicted at optimum specific speed.

Turbine size parameter:

$$
\mathrm{SP}=\frac{\sqrt{\dot{V}_{\text {out }, s, t}}}{\left(h_{\text {in }, t}-h_{\text {out }, s, t}\right)^{1 / 4}}
$$

Volume flow ratio between turbine outlet and inlet is

$V_{r}=\frac{\dot{V}_{\text {out }, s, t}}{\dot{V}_{i n, t}}$

The isentropic efficiency of single-stage axial-flow turbine is determined by using the correlation of Astolfi and Macchi [23] as follow:

$$
\begin{aligned}
& \eta_{s, t}=0.90831500-0.05248690 X \\
& -0.04799080 X^{2}-0.01710380 X^{3} \\
& -0.00244002 X^{4}+0.04961780 Y \\
& -0.04894860 Y^{2}+0.01171650 Y^{3} \\
& -0.00100473 Y^{4}+0.05645970 X Y \\
& -0.01859440 X Y^{2}+0.01288860 X^{2} Y \\
& +0.00178187 X Y^{3}-0.00021196 X^{2} Y^{3} \\
& +0.00078667 X^{3} Y^{2}
\end{aligned}
$$

where:

$X=\ln (\mathrm{SP})$

$Y=\ln \left(V_{r}\right)$

Heat rate transferred by water-cooled condenser is calculated as follow:

$\dot{Q}_{c}=\dot{m}_{\text {ORC }}\left(h_{\text {out }, t}-h_{\text {in }, p}\right)$
The pump power input and electricity consumption of fan of cooling tower are computed as described in the work of Pidaparti et al. [25].

After determining performance of all components, net power output of the system is defined as the difference between turbo-generator output and the sum of power input of ORC feed pump, cooling water pump and fan of cooling tower.

$\dot{W}_{\text {ORC }}=\dot{W}_{t}-\dot{W}_{p}-\dot{W}_{p, w}-\dot{W}_{f a n}$

The overall system efficiency is defined as the ratio of the system net power output to the heat transfer rate of thermosyphons-based evaporator.

$\eta_{O R C}=\frac{\dot{W}_{O R C}}{\dot{Q}_{h}}$

\section{Performance Evaluation}

For evaluating the performance of ORC system, some parameters, presented in Table 4, are fixed while the evaporating temperature (also corresponding to evaporating pressure) of organic working fluid varies.

An EES [26] code was developed to perform system modelling and simulation. Thermo-physical properties of working fluids are determined using CoolProp platform [27] called from EES program. Several assumptions for the system modelling and simulation are considered as follows:

- Each process of the system is considered as a steady-state process,

- Heat and friction losses in the components are neglected,

- Potential and kinetic energy of the media are neglected,

- As the ORC working fluid, i.e. Cyclopentane, is a dry fluid, organic vapour entering the turbine is assumed at saturated vapour.

Table 4. Parameters for performance evaluation.

\begin{tabular}{ll}
\hline Parameters & Value \\
\hline Fumes inlet temperature, ${ }^{\circ} \mathrm{C}$ & 820 \\
Fumes outlet temperature, ${ }^{\circ} \mathrm{C}$ & 620 \\
Fumes mass flow rate, $\mathrm{kg} / \mathrm{s}$ & 28.75 \\
Condensing temperature, ${ }^{\circ} \mathrm{C}$ & 50 \\
Sub-cooling degree, $\mathrm{K}$ & 10 \\
Condenser pinch point temperature difference, $\mathrm{K}$ & 10 \\
Pump/electrical motor/electrical generator efficiency,- & $0.7 / 0.95 / 0.95$ \\
Internal heat exchanger pinch point temperature & 10 \\
difference, $\mathrm{K}$ & \\
Superheating degree, $\mathrm{K}$ & 0 \\
Water temperature at condenser inlet, ${ }^{\circ} \mathrm{C}$ & 25 \\
Air inlet temperature, ${ }^{\circ} \mathrm{C}$ & 14 \\
Air inlet relative humidity, - & 0.8 \\
Air outlet relative humidity, - & 1 \\
\hline
\end{tabular}

According to the simulation results, a maximum net power output of the system is found at the evaporating temperature of about $214^{\circ} \mathrm{C}$ as shown in Figure 5. Indeed, the basic idea behind all the modifications to increase the ORC system efficiency (corresponding to the net power output for a constant heat transfer rate of the heat source) is to increase the average high temperature (at which heat is transferred to the working fluid from the heat source medium). As can be seen from Figure 5, when evaporating 
temperature increases the net power output of the system increases until the evaporating temperature reaches about $214^{\circ} \mathrm{C}$. Beyond this temperature the increase of evaporating temperature yields a decrease of turbine power output, while the power input of ORC feed pump always increases in function of evaporating temperature and the electricity consumption for cooling water pump and cooling air fan remains constant (cf. Figure 6). This makes the net power output of the whole system calculated by the Eq. (13) decrease.

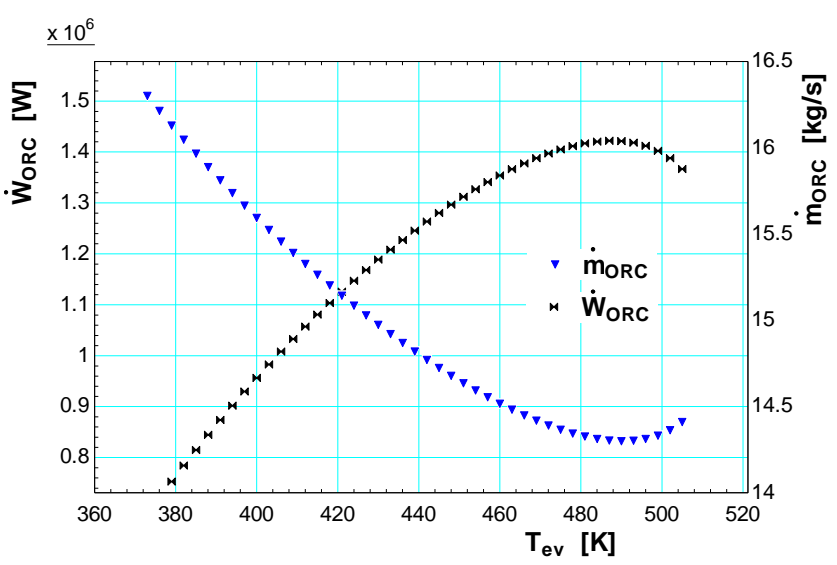

Figure 5. Evolution of ORC net power output and necessary mass flow of working fluid when varying evaporating temperature.

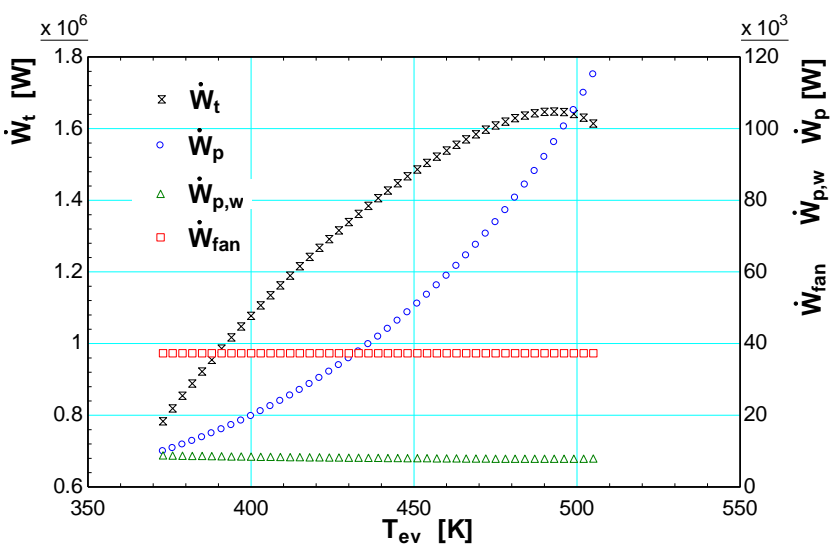

Figure 6. Evolution of turbine power output and power input of ORC feed pump, water cooling pump and cooling tower fan when varying the evaporating temperature.

The reduction of turbine power output when evaporating temperature higher than $214^{\circ} \mathrm{C}$ is explained by comparing the specific enthalpy differences through the evaporator and the turbine as reported in Table 5. When the evaporating temperature increases from $200^{\circ} \mathrm{C}$ to $214^{\circ} \mathrm{C}$, the enthalpy differences of ORC working fluid through the evaporator, $\Delta \mathrm{h}_{\text {evap }}$, increases. This conducts to a mass flow rate reduction of organic fluid as the result of the equation and an imposed heat transfer rate of the evaporator. On the other hand, the enthalpy drop, $\Delta \mathrm{h}_{\mathrm{t}}$, of organic fluid through the turbine also increases. Finally, the turbine power output, calculated as the product of mass flow rate of organic fluid and its enthalpy drop through the turbine, increases. When the evaporating temperature of organic fluid varies from $214^{\circ} \mathrm{C}$ to $228^{\circ} \mathrm{C}$, the enthalpy difference of Cyclopentane through the evaporator decreases. As consequence, the mass flow rate of organic fluid increases. In contrast, the enthalpy drop of Cyclopentane through the turbine decreases. The final combination conducts to a reduction of turbine power output. Moreover, when evaporating temperature is greater than $214^{\circ} \mathrm{C}$, the expansion of saturated vapour at turbine inlet partially takes place in twophase zone (in red oval) as presented in Figure 7. Consequently, a slightly superheating will be needed for ensuring dry expansion of organic fluid through the turbine to avoid blades erosion.

Table 5. Specific enthalpies and enthalpy differences of organic fluid through evaporator and turbines.

\begin{tabular}{ccc}
$T_{\text {evap }}$ & $\Delta h_{\mathrm{t}}$ & $\Delta h_{\text {evap }}$ \\
{$\left[{ }^{\circ} \mathrm{C}\right]$} & {$[\mathrm{J} / \mathrm{kg}]$} & {$[\mathrm{J} / \mathrm{kg}]$} \\
\hline 200 & 111590 & 516508.0 \\
214 & 115199 & 519449.0 \\
228 & 114374 & 517834.0 \\
\hline
\end{tabular}

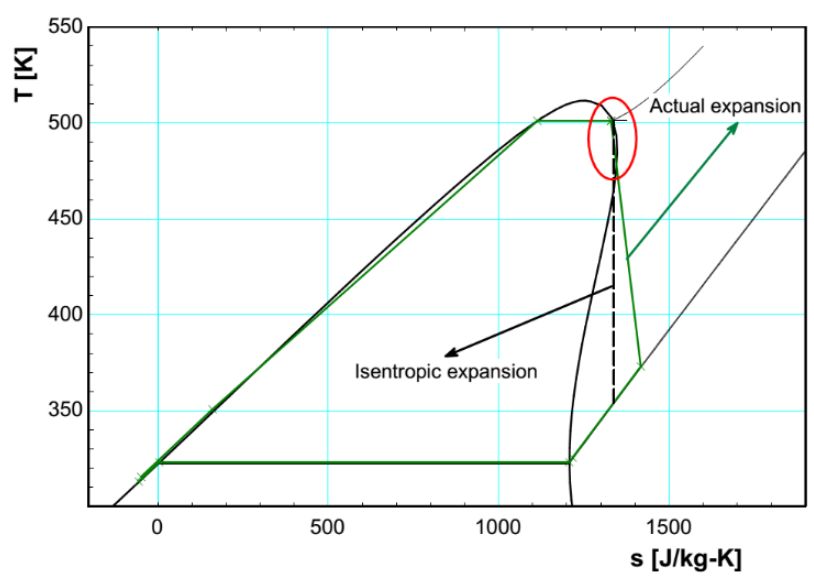

Figure 7. Transformation processes (in green) of Cyclopentane on T-s diagram.

Regarding the turbine isentropic efficiency, it varies from 0.77 to 0.89 and increases with the increase of mass flow rate and the decrease of evaporating temperature of organic working fluid as found in Figure 7. Indeed, the turbine efficiency increases when volume flow ratio decreases and size parameter increases as shown in Figure 8. In practice, a multi-stage axial turbine is often adopted for improving its isentropic efficiency and for avoiding high Mach numbers and large blade height variations across the rotor blade as well as high mechanical stresses [28].

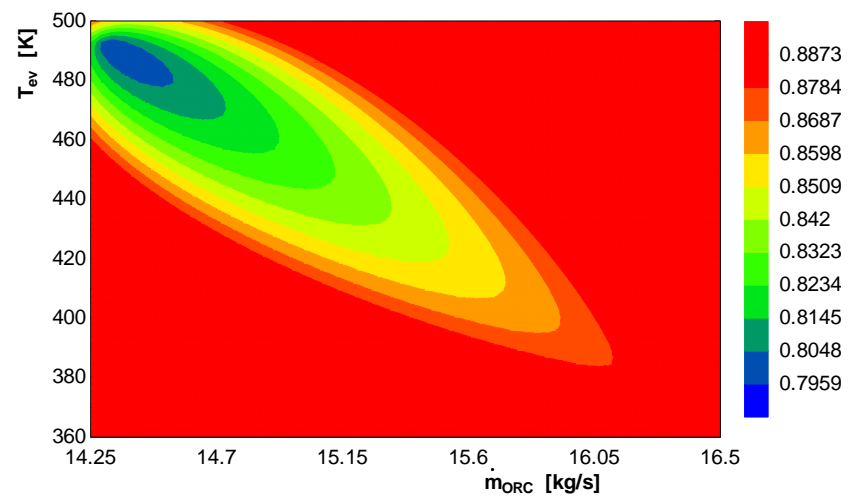

Figure 7. Variation of turbine efficiency. 


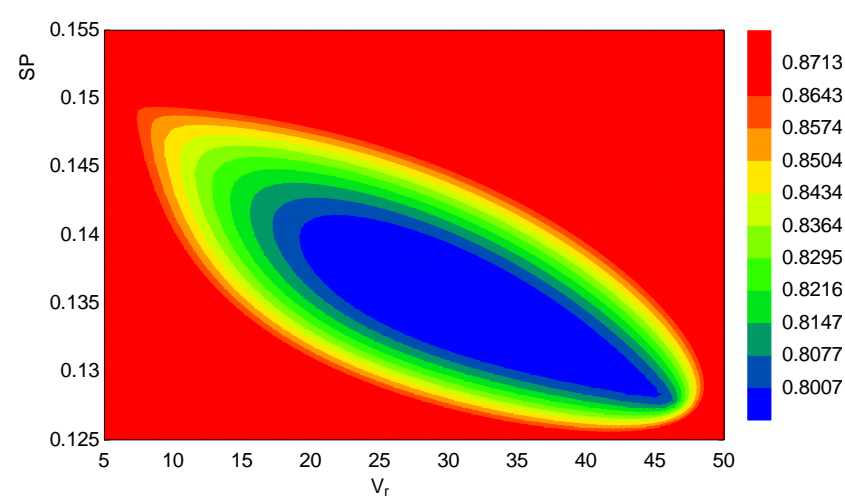

Figure 8. Influence of size parameter and volume flow ratio on turbine efficiency.

\section{Conclusions and Perspectives}

The present work investigates the combination of an ORC and the two-phase closed thermosyphons for capturing and converting heat from RHF off-gases into electricity. A component-based model was developed using EES environment to perform the steady-state modelling as well as the power output optimization of thermosyphonsORC system. Cyclopentane was preliminarily chosen as ORC working medium due to its good thermo-physical properties at relatively high temperature. Indeed, Cyclopentane is thermally and chemically stable when its bulk temperature is kept below $300^{\circ} \mathrm{C}$. However other organic fluids should be also investigated to bring out the most appropriate working medium for such system. The influence of system operating conditions on turbine isentropic efficiency is also evaluated using an empirical correlation for single-stage axial-flow turbine. The turbine isentropic efficiency varies from 0.77 to 0.89 and decreases with a rise of evaporating temperature and a reduction of mass flow rate of organic fluid. Actually, a multi-stage turbine is often used in practice for improving the isentropic efficiency and avoiding high Mach numbers and large blade height variations across the rotor blade as well as high mechanical stresses. By optimization process, the maximum net power output of thermosyphons-ORC system is found when the evaporating temperature of Cyclopentane is about of $214^{\circ} \mathrm{C}$. The maximum net power output of the system is of 1.42 MWel corresponding to a thermal efficiency of 19.1 $\%$.

Theoretically, the use of two-phase closed thermosyphons for transferring thermal energy from heat source to ORC working fluid can improve the system overall efficiency by reducing the power consumption for transporting the heat carrier, e.g. thermal oil, in the case of utilizing an intermediate heat transfer loop. The combination between the ORC technology and the thermosyphons equally presents a real potential for reducing the investment cost and eliminating the safety concern of employing the traditional heat carrier loop or a direct evaporator.

As the temperature difference between the heat source and the organic fluid at evaporator is still high. Some further modification of the system, e.g. superheating the working fluid at turbine inlet, should be considered for improving the system overall efficiency. These modifications should be investigated in parallel with considering economic criteria of the project.

\section{Acknowledgments}

The authors wish to acknowledge the support from the Walloon Public Service for financing the project.

$\begin{array}{ll}\text { Nomenclature } & \text { surface area, } \mathrm{m}^{2} \\ A & \text { capacitance rate, } \mathrm{W} / \mathrm{K} \\ \dot{C} & \text { diameter, } \mathrm{m} \\ D & \text { latent heat of vaporisation, } \mathrm{J} / \mathrm{kg} \\ \Delta h_{l v} & \text { gravitational acceleration, } 9.80665 \mathrm{~m} / \mathrm{s}^{2} \\ g & \text { specific enthalpy, } \mathrm{J} / \mathrm{kg} \\ h & \text { thermal conductivity, W/(m.K) } \\ k & \text { length, } \mathrm{m} \\ L & \text { mass flow rate, } \mathrm{kg} / \mathrm{s} \\ \dot{m} & \text { molecular mass, } \mathrm{g} / \mathrm{mol} \\ \mathrm{MM} & \text { National Fire Protection Association label } \\ \mathrm{NFPA} & \text { Net Positive Suction Head, } \mathrm{m} \\ \mathrm{NSPH} & \text { Ozone Depletion Potential, - } \\ \mathrm{ODP} & \text { absolute pressure, } \mathrm{Pa} \\ P & \text { heat rate, } \mathrm{W} \\ \dot{Q} & \text { Thermal resistance, } \mathrm{K} / \mathrm{W} \\ R & \text { size parameter, } \mathrm{m} \\ \mathrm{SP} & \text { temperature, }{ }^{\circ} \mathrm{C} \\ T & \text { volume flow rate, } \mathrm{m}^{3} / \mathrm{s} \\ \dot{V} & \text { volume flow ratio, - } \\ V & \text { power, W } \\ \dot{W} & \end{array}$

Greek symbols

$\alpha \quad$ heat transfer coefficient, $\mathrm{W} /\left(\mathrm{m}^{2} . \mathrm{K}\right)$

$\eta \quad$ efficiency, -

$\mu \quad$ viscosity, Pa.s

$\rho$ density, $\mathrm{kg} / \mathrm{m}^{3}$

\section{Subscripts and superscripts}

auto auto ignition temperature

b normal boiling point

c cold or heat sink or condensation

crit critical

IHE internal heat exchanger

in inlet

h hot or heat source

lv liquid/vapour

ORC organic Rankine cycle

out outlet

p pump

sat saturation

$\mathrm{s} \quad$ isentropic

$\mathrm{t}$ turbine

tot total

w water

\section{References:}

[1] General Electric Company (2011). Heat pipes for transferring heat to an organic rankine cycle evaporator. US 20110061386 A1.

[2] J. A. Gruss and P. Pardo, "Systeme de récuperation de l'énergie de la chaleur de gaz chaud(s) et/ou fumée(s), application à la recuperation de l'énergie de fumées encrassantes, en particulier issues de moteurs thermiques," 2016.

[3] D. A. Reay, P. A. Kew, and R. J. McGlen, Heat Pipes Theory, Design and Applications, Oxford UK: Elsevier, 2014. 
[4] R. W. MacGregor, P. A. Kew, and D. A. Reay, "Investigation of low Global Warming Potential working fluids for a closed two-phase thermosyphon," Applied Thermal Engineering, 51, 917-925, 2013.

[5] ESDU, "Heat Pipes - Performance of two-phase Closed Thermosyphons," London, U.K.: Engineering Sciences Data Unit, 1981.

[6] D. F. Isoppo, T. P. F. Borges, and B. H. M. Marcia, "Development of a detailed thermal model for designing heat pipe heat exchangers," in the 22nd International Conference on Efficiency, Cost, Optimization Simulation and Environmental Impact of Energy Systems, Foz do Iguaçu, Parana, Brazil, 2009.

[7] A. Amini, "Heat pipe heat exchangers," in the 30th HEXAG Meeting, Newcastle, UK, 2013.

[8] B. H. M. Marcia, Heat Pipes and Solid Sorption Transformations, CRC Press, 2013.

[9] H. Jouhara, "Heat pipe based systems for industrial and renewable energy management," in the 32nd HEXAG Meeting, Newcastle, UK, 2015.

[10] J. Bonjour, F. Lefèvre, V. Sartre, Y. Bertin, C. Romestant, V. Ayel, et al., "Systèmes diphasiques de contrôle thermique - Thermosiphons et caloducs," Techniques de l'ingénieur, 2010.

[11]A. Žukauskas, "Heat Transfer from Tubes in Crossflow," in Advances in Heat Transfer. vol. Volume 8, P. H. James and F. I. Thomas, Eds., ed: Elsevier, 1972, pp. 93-160.

[12]D. W. Green and R. H. Perry, Perry's chemical engineers' handbook: McGraw-Hill, 2008.

[13]M. G. Cooper, "SATURATION NUCLEATE POOL BOILING - A SIMPLE CORRELATION A2 Simpson, H C," in First U.K. National Conference on Heat Transfer, G. F. Hewitt, D. Boland, T. R. Bott, B. N. Furber, W. B. Hall, P. J. Heggs, et al., Eds., ed: Pergamon, 1984, pp. 785-793.

[14]M. Groll and S. Rösler, "Operation principles and performance of heat pipes and closed two-phase thermosyphons," Journal of Non-Equilibrium Thermodynamics, 17, 91-151, 1992.

[15] T. Bause, F. Campana, L. Filippeni, A. Foresti, N. Monti, and T. Pelz, "Cogeneration with ORC at ElbeStahlwerke Feralpi EAF Shop," in the the AISTech Conference, Indianapolis, IN, 2014.

[16] O. Badr, S. D. Probert, and P. W. O'Callaghan, "Selecting a working fluid for a Rankine-cycle engine," Applied Energy, 21, 1-42, 1985.
[17] European Comission (2013). EU legislation to control F-gases,. European Comission.

[18] V. L. Le, A. Kheiri, M. Feidt, and S. Pelloux-Prayer, "Thermodynamic and economic optimizations of a waste heat to power plant driven by a subcritical ORC (Organic Rankine Cycle) using pure or zeotropic working fluid," Energy, 78, 622-638, 2014.

[19]Modifications and Optimization of the Organic Rankine Cycle to Improve the Recovery of Waste Heat. (2013). Idoha: Idaho National Laboratory.

[20] P. D. Turco, A. Asti, A. S. D. Greco, A. Bacci, G. Landi, and G. Seghi, "The ORegen ${ }^{\mathrm{TM}}$ Waste Heat Recovery Cycle: Reducing the $\mathrm{CO} 2$ Footprint by Means of Overall Cycle Efficiency Improvement,"in ASME Turbo Expo, Vancouver, British Columbia, Canada, 2011.

[21] Atlas Copco. (n.d.). DELIVERING COMPLETE ORC SOLUTIONS. [online] Available at: http://www.atlascopco-gap.com/fileadmin/download/ brochure/AC-ORC-BRO.pdf [Accessed 15 Feb 2016].

[22] W. D. Seider, J. D. Seader, D. R. Lewin, and S. Widagdo, Product and process design principles: synthesis, analysis, and evaluation, John Wiley, 2010.

[23] M. Astolfi and E. Macchi, "Efficiency correlations for axial flow turbines working with non-conventional fluids," in the 3rd International Seminar on ORC Power Systems, Brussels, Belgium, 2015.

[24]E. Macchi and A. Perdichizzi, "Efficiency Prediction for Axial-Flow Turbines Operating with Nonconventional Fluids," 103, 718-724, 1981.

[25] S. R. Pidaparti, A. Moisseytsev, J. J. Sienicki, and D. Ranjan, "Counter flow induced draft cooling tower option for supercritical carbon dioxide Brayton cycle," Nuclear Engineering and Design, 295, 549-558, 2015.

[26]S. A. Klein, EES: Engineering Equation Solver, Academic P ed., Madison: F-Chart Software, 2013.

[27] I. H. Bell, J. Wronski, S. Quoilin, and V. Lemort, "Pure and Pseudo-pure Fluid Thermophysical Property Evaluation and the Open-Source Thermophysical Property Library CoolProp," Ind Eng Chem Res, 53, 2498-2508, 2014.

[28] M. Astolfi, M. C. Romano, P. Bombarda, and E. Macchi, "Binary ORC (Organic Rankine Cycles) power plants for the exploitation of medium-low temperature geothermal sources - Part B: Technoeconomic optimization," Energy, 66, 435-446, 2014. 